\title{
Contingente zelfwaardering: betrouwbaarheid en validiteit van de Nederlandse globale en domeinspecifieke contingentieschaal
}

\author{
Daphne L. Jansen • Roos Vonk
}

\begin{abstract}
Contingente zelfwaardering is afhankelijk van bepaalde factoren, zoals iemands uiterlijk, prestaties of goedkeuring door anderen. Er werden twee Nederlandse schalen ontwikkeld: een schaal die uitgaat van globale contingentie (contingentie van zelfwaardering als globale individuele verschilvariabele), en een schaal die uitgaat van domeinspecifieke contingentie (waarbij mensen vooral verschillen in de domeinen waarop ze contingent zijn, bijvoorbeeld prestaties versus sociale acceptatie). Beide schalen werden onderzocht op interne consistentie en factoriële, convergente, discriminante en constructvaliditeit. De resultaten suggereren dat een globale benadering van contingentie voor de meeste doeleinden volstaat en dat domeinspecifieke contingenties overwegend manifestaties zijn van de algehele geneigdheid de zelfwaardering te ontlenen aan bepaalde factoren. Contingentie is positief gerelateerd aan vijandigheid en instabiliteit van zelfwaardering, en negatief aan niveau van zelfwaardering.
\end{abstract}

\section{Inleiding}

Gedurende de afgelopen decennia is het onderzoek naar zelfwaardering enorm toegenomen. In tabel 1 is te zien dat binnen de psychologie het aantal publicaties over het zelf in de loop der tijd sterk is gestegen. De interesse in zelfwaardering is onder meer gevoed door de suggestie dat lage zelfwaardering sociale problemen tot gevolg kan

Daphne L. Jansenen, Radboud Universiteit Nijmegen,

Vakgroep Sociale Psychologie, Postbus 9104, 6500 HE

Nijmegen. E-mail: vonk@psych.ru.nl. Met dank aan Jan van

Leeuwe, June Tangney, Jennifer Crocker, Michael Kernis en

Mark Dechesne. hebben, en dat het verhogen van de zelfwaardering deze problemen zou kunnen oplossen (Crocker \& Wolfe, 2001; Baumeister, Campbell, Krueger \& Vohs, 2003).

Het begrip zelfwaardering is echter complexer dan men altijd heeft gedacht, en de stelling: 'Hoe meer zelfwaardering, hoe beter', gaat niet zonder meer op. Recentelijk blijkt steeds vaker dat, naast de hoogte van zelfwaardering, ook heel andere aspecten van zelfwaardering van belang zijn, zoals stabiliteit (de mate waarin de zelfwaardering schommelt over de tijd; Kernis, 2003) en contingentie (de mate waarin men zelfwaardering ontleent aan bepaalde factoren, zoals prestaties, sociale goedkeuring en uiterlijke aantrekkelijkheid). Iemand die zich alleen waardevol voelt wanneer hij er goed uitziet, door anderen aardig behandeld wordt of goede prestaties levert, heeft contingente zelfwaardering. Contingentie is in principe onafhankelijk van hoe hoog de zelfwaardering is - er is hoge en lage contingente zelfwaardering - maar komt in de praktijk vaker voor bij lage zelfwaardering.

Globale en domeinspecifieke contingentie

Er zijn twee verschillende benaderingen van contingente zelfwaardering. De 'between-person'-benadering ofwel globale benadering (Deci \& Ryan, 1995) beschouwt contingentie als een globaal kenmerk waarin individuele verschillen bestaan. Deze visie is gebaseerd op de 'selfdetermination'-theorie (Deci \& Ryan, 1985). Deze theorie beschrijft dat gedrag door verschillende factoren kan worden gemotiveerd. Zo kunnen mensen tot bepaald gedrag worden aangezet vanuit een innerlijke overtuiging of interesse (intrinsiek) of als gevolg van druk van buitenaf (extrinsiek; Ryan \& Deci, 2000). De eerste groep mensen staat meer in contact met zichzelf en beschikt 
Tabel 1 Verhouding tussen het totale aantal publicaties binnen de psychologie en het aantal publicaties over het zelf, per tijdsperiode van twintig jaar.

\begin{tabular}{llll}
\hline Periode & Totaal aantal publicaties & Aantal publicaties zelf & $\%$ \\
\hline $1872-1900$ & 361 & 23 & 6,37 \\
$1901-1920$ & 3.403 & 121 & 3,56 \\
$1921-1940$ & 82.918 & 2.521 & 3,04 \\
$1941-1960$ & 136.607 & 5.064 & 3,71 \\
$1961-1980$ & 420.589 & 36.134 & 8,59 \\
$1981-2000$ & 1.025 .556 & 131.175 & 12,79 \\
\hline
\end{tabular}

over een hoge mate van autonomie; dit is gerelateerd aan niet-contingente, 'echte' zelfwaardering. De laatste groep laat zich meer beïnvloeden door extrinsieke factoren (bijv. behoefte om aardig gevonden te worden of om succesvol te zijn); dit is gerelateerd aan contingente zelfwaardering.

Volgens de 'within-person'-benadering ofwel domeinspecifieke benadering (Crocker \& Wolfe, 2001) heeft iedereen tot op zekere hoogte contingente zelfwaardering. Echter, de domeinen waarvan de zelfwaardering afhangt, verschillen van persoon tot persoon. De een ontleent zelfwaardering bijvoorbeeld aan uiterlijke aantrekkelijkheid, de ander aan hechte familiebanden. Andere belangrijke domeinen waaraan volgens Crocker en collega's (Crocker \& Wolfe, 2001; Crocker, Sommers \& Luhtanen, 2002) zelfwaardering kan worden ontleend, zijn sociale goedkeuring, competitie, academische competentie, macht, zelfvertrouwen, lidmaatschap van bepaalde sociale groepen, voldoen aan een eigen ethische standaard en liefde van God.

\section{Contingentie in relatie tot andere variabelen}

Ongeacht welke opvatting men hanteert over contingentie, het is wel duidelijk dat contingentie van zelfwaardering van belang is voor welzijn en sociaal functioneren.

\section{Globale contingentie}

Kernis en Paradise (2003, in Kernis, 2003) onderzochten of globale contingente zelfwaardering vijandigheid in reactie op een egobedreiging kon voorspellen. Zoals verwacht, voelden studentes met een hoge contingente zelfwaardering zich bozer in reactie op een egobedreiging dan studentes met een lage contingente zelfwaardering. ${ }^{1}$ Uit een studie van Neighbors, Larimer, Geisner en Knee (2001, in Kernis, 2003) bleek dat studenten met een hoge globale contingente zelfwaardering alcohol gebruikten met de bedoeling om hun stemming en sociaal functioneren te verbeteren, afwijzing van leeftijdgenoten te

\footnotetext{
${ }^{1}$ Aan dit specifieke onderzoek deden alleen vrouwen mee. De resultaten zijn echter gerepliceerd met mannelijke deelnemers.
}

voorkomen en hun problemen aan te kunnen. Bovendien was contingente zelfwaardering gerelateerd aan een hogere alcoholconsumptie en aan alcoholgerelateerde problemen. Globale contingente zelfwaardering is voorts gerelateerd aan instabiele zelfwaardering (Paradise, 2001, in Kernis, 2003). Ook zijn er aanwijzingen dat hoge contingente zelfwaardering gerelateerd is aan het persoonlijkheidskenmerk narcisme (Rhodewalt, Madrian \& Cheney, 1998).

\section{Domeinspecifieke contingentie}

Bepaalde specifieke contingentiedomeinen zijn geassocieerd met een lagere globale zelfwaardering dan andere (Crocker \& Wolfe, 2001). Zo is het niveau van zelfwaardering negatief gerelateerd aan de meer extrinsieke contingenties (bijv. sociale goedkeuring, uiterlijke schoonheid, competitie). De meer intrinsieke contingenties (bijv. voldoen aan een eigen ethische standaard) zijn zwak positief gerelateerd aan het niveau van zelfwaardering. Crocker, Sommers en Luhtanen (2002) en Crocker, Karpinski, Quinn en Chase (2003) vonden ook een verband tussen instabiliteit van zelfwaardering en specifieke contingentiedomeinen. Studenten die hun zelfwaardering ontleenden aan hun academische competentie, vertoonden grotere fluctuaties in hun zelfwaardering in reactie op positieve en negatieve academische gebeurtenissen dan anderen. Uiterlijke en competitiecontingentie zijn significant gerelateerd aan narcisme en neurose (Crocker, Luhtanen, Cooper \& Bouvrette, 2003). Uit een studie van Crocker en Luhtanen (2003) bleek dat onder studenten academische competentiecontingentie een voorspeller was van academische en financiële problemen, en dat uiterlijke contingentie een voorspeller was van financiële problemen.

\section{Extrinsieke en intrinsieke contingenties}

Contingenties kunnen extrinsiek of intrinsiek zijn. Extrinsieke contingentiedomeinen reflecteren aspecten van het zelf die men veelal niet zelf in de hand heeft (bijv. prestaties, sociale goedkeuring, uiterlijk). De zelfwaardering die men ontleent aan deze domeinen is 
grotendeels afhankelijk van anderen. Intrinsieke contingentiedomeinen reflecteren aspecten van het zelf die grotendeels onafhankelijk zijn van factoren van buitenaf. Crocker, Luhtanen, Cooper en Bouvrette (2003) meten dit onder andere in het ethische domein door te vragen in hoeverre mensen hun zelfwaardering laten afhangen van de mate waarin ze aan hun eigen ethische standaard voldoen. Paradise en Kernis (1999) hebben tevens intrinsieke contingentie-items opgenomen in hun meting van globale contingentie (bijv. 'De mate waarin ik voldoe aan de eisen die ik aan mezelf stel, bepaalt sterk hoe ik over mezelf denk'). Verondersteld zou kunnen worden dat, wanneer men de zelfwaardering laat afhangen van meer intrinsieke domeinen, men beschikt over een gezonde zelfwaardering, door Kernis geformuleerd als 'optimale zelfwaardering'. Volgens Kernis (2003) is dit echter niet het geval, aangezien optimale zelfwaardering onafhankelijk is van welke evaluatie dan ook. Bij optimale zelfwaardering is de score op elke vorm van contingentie dus laag.

\section{Dit onderzoek}

Het doel van ons onderzoek is in de eerste plaats het ontwikkelen van een Nederlandse schaal voor contingente zelfwaardering. We willen een vragenlijst maken die uitgaat van globale contingentie en een tweede vragenlijst die uitgaat van domeinspecifieke contingentie. De eerste lijst is een vertaling en aanpassing van de Contingent Self-Esteem Scale van Paradise en Kernis (1999) en meet contingentie als een globale individuele verschilvariabele. De schaal bevat tien algemene stellingen waarbij moet worden aangegeven in hoeverre een uitspraak in het algemeen van toepassing is. Voorbeeld-items zijn:

1. 'Als ik goed kan opschieten met iemand, heb ik een beter gevoel over mezelf';

2. 'Als ik ergens succesvol in ben, blijft mijn gevoel van eigenwaarde gelijk' (omgekeerd geformuleerd).

De tweede lijst meet de mate waarin de zelfwaardering ontleend wordt aan vier domeinen: sociaal, uiterlijk, prestatie (alle extrinsiek) en innerlijke standaard (intrinsiek). Deze vier domeinen zijn tot stand gekomen nadat we de door Crocker en Wolfe (2001) en Crocker, Sommers en Luhtanen (2002) vastgestelde domeinen hebben gegroepeerd en aangepast aan de Nederlandse cultuur. Een nieuw element is dat onze lijst bestaat uit twee subschalen: een schaal waarbij voor elk van de vier domeinen moet worden aangegeven in hoeverre deze de zelfwaardering verhogen, en een schaal waarbij voor dezelfde domeinen moet worden aangegeven in hoeverre deze de zelfwaardering verlagen. De eerste schaal bestaat uit positief geformuleerde items die betrekking hebben op:

1. prestatie (vier items, bijv. 'een taak met succes volbrengen');
2. uiterlijk (vier items, bijv. 'me aantrekkelijk voelen');

3. sociaal (vier items, bijv. 'aandacht krijgen van anderen');

4. intrinsiek (vier items, bijv. 'een nieuwe kant van mezelf leren kennen').

De tweede schaal bestaat uit negatief geformuleerde items die betrekking hebben op:

1. prestatie (vier items, bijv. 'slechte prestaties leveren');

2. uiterlijk (vier items, bijv. 'te dik zijn');

3. sociaal (vier items, bijv. 'het gevoel hebben dat anderen me niet aardig vinden');

4. intrinsiek (vier items, bijv. 'me anders voordoen dan ik ben').

Onze hoofdvraag is of contingentie een globaal (eendimensioneel) dan wel een domeinspecifiek (meerdimensioneel) kenmerk is. Dit zal aan de hand van de interne consistentie en factoriële, convergente, discriminante en constructvaliditeit van de vragenlijsten worden onderzocht.

\section{Interne consistentie}

Voor het vaststellen van de interne consistentie per schaal en subschaal maken we gebruik van betrouwbaarheidsanalyse met Cronbachs alfa.

\section{Factoriële validiteit}

Volgens Deci en Ryan (1995) en Kernis (2003) is contingentie een eendimensioneel kenmerk. Deze auteurs erkennen dat er verschillende domeinen te onderscheiden zijn (bijv. prestatie, sociaal, uiterlijk en intrinsiek), deze contingenties vloeien echter voort uit een enkele factor. Dit impliceert dat ze onderling sterk gecorreleerd zijn en dat ze op dezelfde wijze gecorreleerd zijn met andere variabelen. Crocker en Wolfe (2001) benaderen contingentie als een meerdimensioneel construct, waarbij de contingentiedomeinen uiteenvallen in verschillende factoren die verschillend gerelateerd zijn aan andere variabelen.

Naast deze twee benaderingen zijn er nog andere modellen denkbaar. Zo is het mogelijk dat verschillende vormen van contingentie uiteenvallen in twee factoren die intrinsieke versus extrinsieke contingenties weerspiegelen. Een andere mogelijkheid is dat er een onderscheid is tussen situaties waarbij de zelfwaardering stijgt of juist daalt (positief, negatief). Iemand bij wie de zelfwaardering stijgt bij bijvoorbeeld goedkeuring, zal niet noodzakelijkerwijs een lagere zelfwaardering krijgen bij afkeuring. Combinaties van deze mogelijkheden zijn ook denkbaar.

Om deze verschillende modellen te onderzoeken maken we gebruik van confirmatieve factoranalyse. 


\section{Convergente validiteit}

De convergente validiteit zal worden bepaald middels de relaties van de scores op zowel de globale als de domeinspecifieke contingentieschaal, met de scores op een vertaalde en aangepaste versie van de Contingencies of Self-Worth Scale van Crocker, Luhtanen, Cooper en Bouvrette (2003).

\section{Discriminante en constructvaliditeit}

De discriminante en constructvaliditeit zullen worden bepaald aan de hand van correlaties van globale en domeinspecifieke contingentie, met andere variabelen die theoretisch of op grond van eerder onderzoek gerelateerd zouden moeten zijn aan contingentie.

1. Niveau van zelfwaardering verwijst naar de hoogte van de zelfwaardering. De meting van het niveau van zelfwaardering kan zowel globaal als domeinspecifiek zijn (bijv. sociale zelfwaardering, prestatiezelfwaardering) (Tafarodi \& Swann, 1995; Kirkpatrick, Waugh, Valencia \& Webster, 2002). Wij verwachten dat contingente zelfwaardering, als in eerder onderzoek (Crocker \& Wolfe, 2001; Crocker, Luhtanen, Cooper \& Bouvrette, 2003), negatief gecorreleerd is met niveau van zelfwaardering (hypothese 1a). Meer specifiek verwachten we dat globale contingentie negatief gerelateerd is aan globale zelfwaardering en dat domeinspecifieke contingentie (bijv. sociale contingentie) negatief gerelateerd is aan de corresponderende domeinspecifieke zelfwaardering, in dit geval sociale zelfwaardering (hypothese 1b).

2. Stabiliteit van zelfwaardering verwijst naar schommelingen van de zelfwaardering over de tijd (Kernis, 2003). Verwacht kan worden dat contingente en instabiele zelfwaardering aan elkaar gerelateerd zijn (Crocker, Sommers \& Luhtanen, 2002; Paradise, 2001, in Kernis, 2003). Wanneer de zelfwaardering afhankelijk is van prestaties of beloning/goedkeuring, zullen er ook meer fluctuaties zitten in de zelfwaardering (hypothese 2).

3. Narcisme als persoonlijkheidseigenschap wordt gekenmerkt door het gevoel dat men superieur is aan anderen. In een studie van Rhodewalt, Madrian en Cheney (1998) was narcisme gerelateerd aan instabiele zelfwaardering. Deze relatie wordt door Morf en Rhodewalt (2001) als volgt verklaard: 'The very fact that the narcissistic self is such a grandiose and bloated structure builds in an inherent vulnerability. It is a self that cannot stand on its own, as it is not grounded in an objective reality, thus it needs constant shoring up and reinforcement' (p. 179). We verwachten dat ook contingente zelfwaardering geassocieerd zou kunnen zijn met narcisme (hypothese 3 ).
4. Agressief en vijandig gedrag is gerelateerd aan instabiele zelfwaardering (Kernis, Granneman \& Barclay, 1989; Baumeister, Smart \& Boden, 1996; Bushman \& Baumeister, 1998). Hetzelfde zou kunnen gelden voor contingente zelfwaardering (Kernis \& Paradise, 2003, in Kernis, 2003). Wanneer de zelfwaardering afhankelijk is van de omgeving, is er meer te verliezen en zal men wellicht vijandiger reageren op kritiek of afwijzing. Vijandigheid kan zowel globaal als domeinspecifiek worden gemeten. Globale vijandigheid verwijst naar vijandigheid in reactie op een algemene egobedreiging; we veronderstellen dat deze is geassocieerd met globale contingentie (hypothese 4a). Domeinspecifieke vijandigheid treedt op in reactie op een egobedreiging binnen een bepaald domein (bijv. falen op het gebied van prestaties, afwijzing op het sociale terrein). We verwachten dat domeinspecifieke contingenties gecorreleerd zijn met de bijbehorende domeinspecifieke vijandigheid (hypothese 4b).

\section{Intrinsieke/extrinsieke en zelfwaardering verhogende/ verlagende contingenties}

Tot slot willen we nagaan of $a$ intrinsieke en extrinsieke contingentiedomeinen, en $b$ contingenties die zelfwaardering verhogen dan wel verlagen, verschillend gerelateerd zijn aan andere variabelen. We verwachten dat een hoge zelfwaardering gerelateerd is aan intrinsieke contingenties en een lage zelfwaardering aan extrinsieke contingenties (hypothese 5a). Ook verwachten we dat een hoge zelfwaardering gerelateerd is aan contingenties die zelfwaardering verhogen, en een lage zelfwaardering aan contingenties die zelfwaardering verlagen (hypothese $5 b$ ). In lijn met deze verwachting ligt onze hypothese dat narcisme met name gerelateerd zal zijn aan intrinsieke contingenties (hypothese 6a) en contingenties die zelfwaardering verhogen (hypothese 6b), aangezien deze contingenties het minst risicovol zijn en op deze manier het kwetsbare en onrealistische zelfbeeld in stand kan worden gehouden. Verder verwachten we dat vijandigheid met name gerelateerd is aan extrinsieke contingenties (hypothese 7a) en contingenties die zelfwaardering verlagen (hypothese 7b). Agressie ontstaat bij een discrepantie tussen wat men zou willen en wat er daadwerkelijk lijkt te gebeuren. De kans daarop is, naar men mag aannemen, groter wanneer men afhankelijk is van extrinsieke factoren (bijv. sociale goedkeuring, prestaties en uiterlijk).

\section{Methode}

\section{Deelnemers}

De verschillende vragenlijsten in dit onderzoek zijn afgenomen als onderdeel van een groter onderzoek over 
zelfbeeld, geluk en motivatie (Vonk, Jolij, Stoeller \& Boog, in voorbereiding; Vonk, 2003). De deelnemers zijn geworven via internetlinks en artikelen (o.a. in $P s y$ chologie Magazine, Intermediair, De Gelderlander en NRCHandelsblad). Aan het onderzoek werd deelgenomen door 4311 personen (1223 mannen, 3070 vrouwen en 18 personen waarvan het geslacht onbekend is ${ }^{2}$ ) met een gemiddelde leeftijd van 39 jaar, variërend van 16 tot 83 . In ruil voor deelname maakten de deelnemers middels een loterij kans op prijzen (naar keuze een boekenbon, cd-bon of vvv-bon) ter waarde van twintig tot vijftig euro en ontvingen ze aan het eind van het onderzoek een overzicht van hun persoonlijke resultaten/scores.

De vragenlijsten die in ons onderzoek van belang zijn, zijn op verschillende tijdstippen ingevuld, gedurende een periode van ongeveer een jaar. Niet alle deelnemers hebben aan elke meting meegedaan. De $N$ per vragenlijst kan dus verschillen.

\section{Procedure}

De deelnemers beantwoordden gedurende een periode van twaalf maanden vragenlijsten thuis achter de computer (voor een overzicht van schalen en metingen in dit onderzoek zie Materiaal). Tijdens de aanmelding via internet vulden ze de achtergrondvragen in. Hierna ontvingen ze per e-mail een codenaam en wachtwoord, zodat zij steeds als er een meting plaatsvond toegang konden krijgen tot de site. Er waren in totaal tien metingen (december 2002-april 2003) met intervallen van een of twee weken daartussen en twee vervolgmetingen (juni-augustus 2003 en oktobernovember 2003). Een meting bestond uit vier tot zeven vragenlijsten en duurde twintig tot 35 minuten. Sommige vragenlijsten werden meermalen, gedurende verschillende metingen afgenomen. Voor elke voltooide meting ontvingen de deelnemers een lotnummer. Gedurende de periode van afname vond er vijfmaal een trekking plaats.

\section{Materiaal}

Er werd gebruik gemaakt van de volgende vragenlijsten.

\section{Zelfwaardering}

Globale zelfwaardering (meting 1 en 4) werd gemeten middels een vertaalde en aangepaste versie van de SelfEsteem Scale van Rosenberg (1965), bestaande uit tien items. Deelnemers moesten aangeven in hoeverre de uitspraken in het algemeen op hen van toepassing waren. Voorbeeld-items:

1. 'Ik vind dat ik een aantal goede kwaliteiten heb';

\footnotetext{
${ }^{2}$ De antwoorden op de achtergrondvragen van zeventien deelnemers zijn zoek geraakt.
}

2. 'Ik ben geneigd mezelf een mislukkeling te vinden' (omgekeerd geformuleerd).

Instabiliteit van zelfwaardering (meting 1, 2, 3, 6, 7 en 8) werd berekend volgens de werkwijze van Greenier, Kernis en Waschull (1995), door per deelnemer de standaarddeviatie te nemen van de scores op zes metingen van de vertaalde State Self-esteem Scale van Heatherton en Polivy (1991) op verschillende tijdstippen. De schaal bestond uit tien items. Deelnemers moesten aangeven in hoeverre de uitspraken op dat moment op hen van toepassing waren. Voorbeeld-items:

1. 'Ik heb op dit moment vertrouwen in mijn capaciteiten';

2. 'Ik voel me op dit moment minderwaardig ten opzichte van anderen' (omgekeerd geformuleerd).

Domeinspecifieke zelfwaardering (meting 10 en 12) werd gemeten middels drie subschalen, elk bestaande uit tien items, waarbij de deelnemers moesten aangeven in hoeverre een uitspraak in het algemeen op hen van toepassing was. Prestatiezelfwaardering werd gemeten met een vertaalde versie van de schaal van Tafarodi en Swann (1995). Voorbeeld-items:

1. 'Dankzij mijn capaciteiten heb ik veel mogelijkheden';

2. 'Ik kan slecht met uitdagingen overweg' (omgekeerd geformuleerd) (meting 10).

Sociale zelfwaardering werd gemeten met een schaal van Vonk e.a. (in voorbereiding). Voorbeeld-items:

1. 'De mensen in mijn omgeving vinden mij leuk zoals ik ben';

2. 'Ik heb vaak het gevoel dat ik anderen te veel ben' (omgekeerd geformuleerd) (meting 10).

Uiterlijke zelfwaardering werd gemeten middels een door ons geconstrueerde schaal. Voorbeeld-items:

1. 'Ik ben tevreden met mijn lichaam';

2. 'Als het zou kunnen, zou ik van alles laten veranderen aan mijn gezicht' (omgekeerd geformuleerd) (meting 12).

\section{Contingentie van zelfwaardering}

Globale contingente zelfwaardering (GCZW; meting 4) werd gemeten middels een vertaalde en aangepaste versie van de Contingent Self-Esteem Scale van Paradise en Kernis (1999), bestaande uit tien items.

Domeinspecifieke contingente zelfwaardering (DCZw; meting 10) werd gemeten middels een door ons geconstrueerde schaal (Vonk e.a., in voorbereiding) bestaande uit 32 items, met vier items voor elk van de acht factoren (sociaal positief/negatief, uiterlijk positief/negatief, prestatie positief/negatief en intrinsiek positief/negatief). 
Contingenties van zelfwaarde (meting 12) werd gemeten met een vertaalde en aangepaste versie van de schaal van Crocker, Luhtanen, Cooper en Bouvrette (2003), in ons onderzoek opgenomen om de convergente validiteit van de andere schalen van contingentie te bepalen. De vragenlijst bestond uit vijftien items, met vijf items voor elk van de domeinen sociaal, uiterlijk en prestatie. De deelnemers moesten aangeven in hoeverre elk van de uitspraken op hen van toepassing was. Voorbeeld-items:

1. 'Het makkt me weinig uit wat anderen van me denken' (omgekeerd geformuleerd) (sociaal);

2. 'Ik heb een beter gevoel over mezelf als ik er goed uitzie' (uiterlijk);

3. 'Als mijn prestaties tekortschieten, heb ik een slecht gevoel over mezelf' (prestatie).

\section{Overige variabelen}

Narcisme (meting 5) werd gemeten middels een vertaalde en ingekorte versie van de Abridged Narcissistic Personality Inventory van Emmons (1987), bestaande uit zeventien items. De deelnemers moesten aangeven in hoeverre een uitspraak in het algemeen op hen van toepassing was. Voorbeeld-items:

1. 'Ik heb meer talenten dan andere mensen';

2. 'Ik voel dat ik een zeer bijzondere persoon ben'.

Globale vijandigheid (meting 9) werd gemeten met een vertaalde, aangepaste en ingekorte versie van de Anger Response Inventory for Adults (ARI; Tangney e.a., 1996). De schaal bestond uit zes hypothetische egobedreigende scenario's. Per scenario werden drie vragen gesteld over hoe boos men zou zijn en hoe men zou reageren. Voorbeeldscenario's:

1. 'U ontdekt dat een "vriend(in)" achter uw rug om over u heeft gepraat';

2. 'U staat in de rij te wachten voor een film en iemand dringt voor'.

Vragen:

1. 'Hoe boos zou u zijn in deze situatie?';

2. 'In hoeverre zou u behoefte hebben de persoon af te straffen?';

3. 'In hoeverre zou u de behoefte hebben stoom af te blazen?'

Domeinspecifieke vijandigheid (meting 12) werd gemeten met een door ons geconstrueerde schaal, gebaseerd op de Anger Response Inventory for Adults (ARI; Tangney e. a., 1996). De deelnemers werden aselect aan een van drie condities toegewezen. Elke groep deelnemers kreeg drie egobedreigende situaties te lezen die betrekking hebben op prestaties (bijv. ' $U$ maakt een opmerking die door een collega of kennis als "dom" wordt bestempeld'), sociale acceptatie (bijv. 'Iemand uit uw vriendenkring geeft een feestje en iedereen is uitgenodigd, behalve u') ofwel op uiterlijk (bijv. 'Tijdens een romantisch afspraakje met iemand krijgt $\mathrm{u}$ te horen dat $\mathrm{u}$ qua uiterlijk niet echt zijn/ haar type bent'). Per scenario werd aan de hand van dezelfde vragen als bij globale vijandigheid de mate van domeinspecifieke vijandigheid gemeten.

Alle vragen werden beantwoord op zevenpuntsschalen. Bij elke meting werd de deelnemers vooraf verzocht zo eerlijk mogelijk te antwoorden en aan te geven hoe het daadwerkelijk was, en niet hoe ze vonden dat het zou moeten zijn.

\section{Resultaten}

Interne consistentie en factoriële validiteit

De globale contingentieschaal werd onderworpen aan een factoranalyse. Op grond van het eigenwaarde-knikcriterium was er sprake van een factor (eigenwaarden factor 1, 2 en 3, resp. 3,95, 1,26 en 0,96) die 33 procent van de variantie verklaarde. De vragen en hun lading op de eerste factor staan vermeld in tabel 2. De interne consistentie van resulterende schaal bedroeg 0,82 .

Om na te gaan welk model het beste overeenkomt met de vragenlijst voor verschillende domeinspecifieke contingenties, maakten we gebruik van confirmatieve factoranalyses. De fit werd bepaald aan de hand van:

1. Chi-kwadraat ${ }^{3}$;

2. 'goodness of fit' (GFI; Bentler, 1983);

3. 'adjusted-GFI' (AGFI; Bentler, 1983);

4. 'normed fit index' (NFI; Bentler \& Bonett, 1980);

5. 'root-mean-square error of approximation'4 (RMSEA; Steiger \& Lind, 1980, in Hu \& Bentler, 1998).

Een GFI, AGFI en NFI groter dan 0,90 betekent dat het model acceptabel is (Bentler \& Bonett, 1980). Voor RMSEA geldt dat een waarde kleiner dan 0,05 een indicator is van een goede fit, waarden tussen de 0,05 en 0,08 wijzen op een redelijk goede fit en waarden groter dan 0,10 weerspiegelen een slechte fit (Browne \& Cudeck, 1993).

Confirmatieve factoranalyses, uitgevoerd met AMOS 4.0 (Arbuckle \& Wothke, 1999), over de 32 items van de domeinspecifieke schaal lieten zien dat het model met acht factoren de beste fit levert in vergelijking met het eenfactormodel, tweefactorenmodel (positief versus negatief, of intrinsiek versus extrinsiek) en vierfactorenmodel

\footnotetext{
${ }^{3}$ Een niet-significante ? wil zeggen dat er sprake is van een goede fit. Echter, triviale verschillen kunnen leiden tot een significante? in grote steekproeven zoals de onze.

${ }^{4}$ RMSEA houdt rekening met de complexiteit van het model, in tegenstelling tot Chi-kwadraat en is daardoor een betrouwbaardere maat voor de fit in grote steekproeven.
} 
Tabel 2 Items en factorladingen in eenfactoroplossing van de schaal voor Globale Contingentie Zelfwaardering (GCZw). Geef bij elk van de onderstaande uitspraken aan in hoeverre de uitspraak voor u geldt in het algemeen.

Als ik slechte prestaties lever, daalt mijn gevoel van eigenwaarde. Globale contingentie

De mate waarin ik voldoe aan de eisen die ik aan mezelf stel, bepaalt sterk hoe ik over mezelf denk. 0,64

Mijn gevoel van eigenwaarde wordt voor een belangrijk deel bepaald door mijn lichamelijke aantrekkelijkheid. 0,52

Ik heb een beter gevoel over mezelf als ik het idee heb dat anderen aardige dingen over me zeggen. 0,76

Als iemand zegt dat ik er goed uitzie, heb ik gelijk een beter gevoel over mezelf in het algemeen.

Als ik ergens succesvol in ben, blijft mijn gevoel van eigenwaarde gelijk. ${ }^{*} \quad 0,32$

Als ik weet dat iemand me aardig vindt, ga ik daardoor ook mezelf aardiger vinden.

Zelfs op dagen dat ik er slecht uitzie, is mijn gevoel van wat ik waard ben hetzelfde als altijd. ${ }^{*} 0,51$

Als ik goed kan opschieten met iemand, heb ik een beter gevoel over mezelf. 0,65

Als mijn prestaties voldoen aan de eisen die ik mezelf gesteld heb, geeft me dat een heel goed gevoel over mezelf. 0,38

* omgekeerd gescoord.

(sociaal, uiterlijk, prestatie en intrinsiek) (zie tabel 3). In tabel 4 staan de items en factorladingen van het achtfactorenmodel. De acht factoren zijn: positief sociaal, uiterlijk, prestatie, intrinsiek en negatief sociaal (waaruit een item verwijderd is vanwege lage factorlading), uiterlijk, prestatie, intrinsiek. De interne consistenties van deze acht schalen variëren van 0,78 tot 0,85 en zijn weergegeven in de bovenste helft van tabel 5 .

Tabel 3 Fit van vijf getoetste modellen in confirmatieve factoranalyse.

\begin{tabular}{lllllll}
\hline & $?^{2}$ & $D F$ & GFI & AGFI & NFI & RMSEA \\
\hline eenfactormodel & $29904,20^{*}$ & 431 & 0,53 & 0,46 & 0,49 & 0,14 \\
tweefactorenmodel (positief-negatief) & $27088,52^{*}$ & 431 & 0,56 & 0,50 & 0,54 & 0,13 \\
tweefactorenmodel (intrinsiek-extrinsiek) & $26715,44^{*}$ & 432 & 0,57 & 0,50 & 0,55 & 0,13 \\
vierfactorenmodel (soc, prestatie, uiterlijk, intr.) & $15947,04^{*}$ & 399 & 0,64 & 0,57 & 0,71 & 0,11 \\
achtfactorenmodel (soc, prestatie, uiterlijk, intr. & $4990,79^{*}$ & 403 & 0,91 & 0,89 & 0,92 & 0,06 \\
X positief-negatief) & & & & & & \\
\hline
\end{tabular}

${ }^{*} p<0,001$.

Tabel 4 Domeinspecifieke contingentie-items en factorladingen in achtfactorenoplossing.

\begin{tabular}{|c|c|c|c|c|c|c|c|c|}
\hline \multirow{2}{*}{$\begin{array}{l}\text { Wilt u bij elk van deze factoren aangeven in hoeverre uw zelfwaardering hierdoor } \\
\text { wordt verhoogd? }\end{array}$} & \multicolumn{8}{|c|}{ Domeinspecifieke contingentiefactoren } \\
\hline & 1 & 2 & 3 & 4 & 5 & 6 & 7 & 8 \\
\hline \multicolumn{9}{|l|}{$\overline{\text { Sociaal }}$} \\
\hline Waardering van anderen krijgen. & 0,78 & & & & & & & \\
\hline Aandacht krijgen van anderen. & 0,72 & & & & & & & \\
\hline Me geliefd voelen. & 0,72 & & & & & & & \\
\hline Steun van anderen krijgen. & 0,62 & & & & & & & \\
\hline \multicolumn{9}{|l|}{ Uiterlijk } \\
\hline Er goed uit zien. & & 0,87 & & & & & & \\
\hline Me aantrekkelijk voelen. & & 0,82 & & & & & & \\
\hline Er goed verzorgd bijlopen. & & 0,76 & & & & & & \\
\hline Op mijn goede gewicht zijn. & & 0,52 & & & & & & \\
\hline \multicolumn{9}{|l|}{ Prestatie } \\
\hline Goede prestaties leveren. & & & 0,83 & & & & & \\
\hline Een taak met succes volbrengen. & & & 0,81 & & & & & \\
\hline Bekwaam zijn in wat ik doe. & & & 0,72 & & & & & \\
\hline Resultaat zien van mijn werk. & & & 0,70 & & & & & \\
\hline \multicolumn{9}{|l|}{ Intrinsiek } \\
\hline Mezelf beter leren kennen. & & & & 0,79 & & & & \\
\hline
\end{tabular}


Tabel 4 (continued)

Wilt u bij elk van deze factoren aangeven in hoeverre uw zelfwaardering hierdoor Domeinspecifieke contingentiefactoren wordt verhoogd?

\begin{tabular}{|c|c|c|c|c|c|c|c|c|}
\hline & 1 & 2 & 3 & 4 & 5 & 6 & 7 & 8 \\
\hline Aandacht geven aan mijn gevoelens. & & & & 0,73 & & & & \\
\hline Een nieuwe kant van mezelf ontdekken. & & & & 0,63 & & & & \\
\hline Tijd nemen voor mezelf. & & & & 0,58 & & & & \\
\hline
\end{tabular}

Wilt u bij elk van deze factoren aangeven in hoeverre uw zelfwaardering hierdoor Domeinspecifieke contingentiefactoren wordt verlaagd?

\begin{tabular}{|c|c|c|c|c|c|c|c|c|}
\hline & 1 & 2 & 3 & 4 & 5 & 6 & 7 & 8 \\
\hline \multicolumn{9}{|l|}{ Sociaal } \\
\hline Het gevoel hebben dat anderen me afkeuren. & & & & & 0,85 & & & \\
\hline Het gevoel hebben dat anderen me niet aardig vinden. & & & & & 0,84 & & & \\
\hline Genegeerd worden door anderen. & & & & & 0,74 & & & \\
\hline \multicolumn{9}{|l|}{ Uiterlijk } \\
\hline Me onaantrekkelijk voelen. & & & & & & 0,88 & & \\
\hline Er slecht uit zien. & & & & & & 0,83 & & \\
\hline Er onverzorgd bij lopen. & & & & & & 0,71 & & \\
\hline Te dik zijn. & & & & & & 0,60 & & \\
\hline \multicolumn{9}{|l|}{ Prestatie } \\
\hline Slechte prestaties leveren. & & & & & & & 0,80 & \\
\hline Falen in een taak. & & & & & & & 0,73 & \\
\hline Me onbekwaam of dom voelen. & & & & & & & 0,72 & \\
\hline Het gevoel hebben dat mijn kennis of inzicht tekort schiet. & & & & & & & 0,62 & \\
\hline \multicolumn{9}{|l|}{ Intrinsiek } \\
\hline Niet trouw zijn aan mezelf. & & & & & & & & 0,79 \\
\hline Tegen mijn geweten in gaan. & & & & & & & & 0,69 \\
\hline Mijn eigen gevoelens niet serieus nemen. & & & & & & & & 0,68 \\
\hline Me anders voordoen dan ik ben. & & & & & & & & 0,66 \\
\hline
\end{tabular}

De correlatie tussen de globale contingentieschaal en de totale score op de domeinspecifieke schaal is 0,51 . In de onderste helft van tabel 5 zijn de onderlinge correlaties tussen de verschillende contingenties weergegeven. Globale contingente zelfwaardering correleert hoger met negatieve contingenties, met name met negatieve sociale contingentie, dan met positieve contingenties. Opvallend is dat globale contingentie niet gerelateerd is aan intrinsieke contingenties.

Tabel 5 Gemiddelden, standaarddeviaties, alfa's en onderlinge Pearson-correlaties van globale contingentie en domeinspecifieke contingenties.

\begin{tabular}{|c|c|c|c|c|c|c|c|c|c|}
\hline & Globaal & $\begin{array}{l}\text { Sociaal } \\
\text { positief }\end{array}$ & $\begin{array}{l}\text { Uiterlijk } \\
\text { positief }\end{array}$ & $\begin{array}{l}\text { Prestatie } \\
\text { positief }\end{array}$ & $\begin{array}{l}\text { Intrinsiek } \\
\text { positief }\end{array}$ & $\begin{array}{l}\text { Sociaal } \\
\text { negatief }\end{array}$ & $\begin{array}{l}\text { Uiterlijk } \\
\text { negatief }\end{array}$ & $\begin{array}{l}\text { Prestatie } \\
\text { negatief }\end{array}$ & $\begin{array}{l}\text { Intrinsiek } \\
\text { negatief }\end{array}$ \\
\hline$M$ & 4,69 & 5,68 & 5,18 & 6,02 & 5,20 & 5,18 & 4,57 & 5,20 & 5,37 \\
\hline$S D$ & 0,90 & 0,86 & 1,12 & 0,73 & 1,00 & 1,29 & 1,26 & 1,06 & 1,07 \\
\hline Alfa & 0,82 & 0,79 & 0,81 & 0,85 & 0,78 & 0,85 & 0,84 & 0,81 & 0,79 \\
\hline $\begin{array}{l}\text { Sociaal } \\
\text { positief }\end{array}$ & $0,44^{*}$ & & & & & & & & \\
\hline Uiterlijk positief & $0,38^{*}$ & $0,49^{*}$ & & & & & & & \\
\hline Prestatiepositief & $0,29^{*}$ & $0,48^{*}$ & $0,42^{*}$ & & & & & & \\
\hline Intrinsiek positief & 0,02 & $0,32^{*}$ & $0,31^{*}$ & $0,24^{*}$ & & & & & \\
\hline Sociaal negatief & $0,54^{*}$ & $0,57^{*}$ & $0,30^{*}$ & $0,26^{*}$ & $0,06^{*}$ & & & & \\
\hline Uiterlijk negatief & $0,46^{*}$ & $0,36^{*}$ & $0,73^{*}$ & $0,26^{*}$ & $0,14^{*}$ & $0,49^{*}$ & & & \\
\hline Prestatienegatief & $0,48^{*}$ & $0,34^{*}$ & $0,27^{*}$ & $0,47^{*}$ & $0,04^{*}$ & $0,58^{*}$ & $0,47^{*}$ & & \\
\hline Intrinsiek negatief & 0,00 & $0,12^{*}$ & $0,09^{*}$ & $0,12^{*}$ & $0,47^{*}$ & $0,14^{*}$ & $0,17^{*}$ & $0,20^{*}$ & \\
\hline
\end{tabular}

${ }^{*} p<0,01$. 
Tabel 6 Pearson-correlaties van de globale en domeinspecifieke contingentieschaal met een vertaalde en aangepaste versie van de 'contingenties van zelfwaarde'schaal van Crocker, Luhtanen, Cooper en Bouvrette (2003).

\begin{tabular}{llllllllll}
\hline & Globaal & $\begin{array}{l}\text { Sociaal } \\
\text { positief }\end{array}$ & $\begin{array}{l}\text { Uiterlijk } \\
\text { positief }\end{array}$ & $\begin{array}{l}\text { Prestatie } \\
\text { positief }\end{array}$ & $\begin{array}{l}\text { Intrinsiek } \\
\text { positief }\end{array}$ & $\begin{array}{l}\text { Sociaal } \\
\text { negatief }\end{array}$ & $\begin{array}{l}\text { Uiterlijk } \\
\text { negatief }\end{array}$ & $\begin{array}{l}\text { Prestatie } \\
\text { negatief }\end{array}$ & $\begin{array}{l}\text { Intrinsiek } \\
\text { negatief }\end{array}$ \\
\hline Totaal & $\mathbf{0 , 6 7 ^ { * }}$ & $0,46^{*}$ & $0,47^{*}$ & $0,32^{*}$ & $-0,01$ & $0,58^{*}$ & $0,54^{*}$ & $0,51^{*}$ & $-0,03$ \\
Sociaal & $0,54^{*}$ & $\mathbf{0 , 3 7 ^ { * }}$ & $0,24^{*}$ & $0,14^{*}$ & $-0,09^{*}$ & $\mathbf{0 , 5 6}^{*}$ & $0,34^{*}$ & $0,40^{*}$ & $-0,06^{*}$ \\
Uiterlijk & $0,55^{*}$ & $0,38^{*}$ & $\mathbf{0 , 6 2}^{*}$ & $0,21^{*}$ & $0,08^{*}$ & $0,42^{*}$ & $\mathbf{0 , 6 3}$ & $0,33^{*}$ & 0,01 \\
Prestatie & $0,54^{*}$ & $0,37^{*}$ & $0,26^{*}$ & $\mathbf{0 , 4 6}^{*}$ & $-0,02$ & $0,43^{*}$ & $0,30^{*}$ & $\mathbf{0 , 5 3}$ & $-0,01$ \\
\hline
\end{tabular}

${ }^{*} p<0,01$.

\section{Convergente validiteit}

In tabel 6 zijn de correlaties van de globale en domeinspecifieke schaal met de vertaalde en aangepaste versie van de schaal van Crocker e.a. (2003) weergegeven. De schalen die onderling sterk zouden moeten correleren, zijn dik gedrukt. Te zien is dat de globale contingentieschaal en de totale score op de contingentieschaal van Crocker e.a. (2003) redelijk correleren. De domeinspecifieke subschalen correleren lager met de corresponderende domeinspecifieke schalen van Crocker e.a. (2003). Dit geldt met name voor de positieve contingentieschalen. De correlaties duiden op een redelijke convergente validiteit van de globale en negatieve domeinspecifieke schalen, en een matige convergente validiteit van de positieve domeinspecifieke schalen.

\section{Discriminante en constructvaliditeit}

Tabel 7 vermeldt de interne consistenties van de schalen globale zelfwaardering, domeinspecifieke zelfwaardering, instabiliteit van zelfwaardering, narcisme, globale vijandigheid, domeinspecifieke vijandigheid, en de correlaties van deze schalen met globale en domeinspecifieke contingentie.

\section{Zelfwaardering}

In de eerste rij van tabel 7 staan de correlaties van globale zelfwaardering met de verschillende contingenties. De correlatie tussen globale contingentie en globale zelfwaardering is $-0,41$, hetgeen hypothese 1a bevestigt. Evidentie voor hypothese $1 \mathrm{~b}$, over domeinspecifieke relaties, is minder overtuigend. In tabel 7 zijn de correlaties van de domeinspecifieke contingenties met de specifieke vormen van zelfwaardering onderstreept. De vet gedrukte correlaties zijn de correlaties tussen corresponderende domeinen. De domeinspecifieke contingenties, met name zelfwaarderingverlagende contingenties, zijn gecorreleerd met de specifieke vormen van zelfwaardering. Echter, deze correlaties zijn zwakker dan de correlatie tussen globale zelfwaardering en globale contingentie. Bovendien worden deze correlaties in het geval van de negatieve contingenties nog lager wanneer er wordt uitgepartialiseerd voor globale contingente zelfwaardering. Dit betekent dat de meeste variantie wordt

Tabel 7 Alfa's en Pearson-correlaties van globale, sociale, uiterlijke, prestatiezelfwaardering, instabiliteit, narcisme, globale, sociale, uiterlijke, prestatievijandigheid met globale contingentie en domeinspecifieke contingenties.

\begin{tabular}{|c|c|c|c|c|c|c|c|c|c|c|}
\hline & & & & & & Contingen & & & & \\
\hline Zelfwaarder & $a$ & Globaal & $\begin{array}{l}\text { Sociaal } \\
\text { positief }\end{array}$ & $\begin{array}{l}\text { Uiterlijk } \\
\text { positief }\end{array}$ & $\begin{array}{l}\text { Prestatie } \\
\text { positief }\end{array}$ & $\begin{array}{l}\text { Intrinsiek } \\
\text { positief }\end{array}$ & $\begin{array}{l}\text { Sociaal } \\
\text { negatief }\end{array}$ & $\begin{array}{l}\text { Uiterlijk } \\
\text { negatief }\end{array}$ & $\begin{array}{l}\text { Prestatie } \\
\text { negatief }\end{array}$ & $\begin{array}{l}\text { Intrinsiek } \\
\text { negatief }\end{array}$ \\
\hline Globaal & 0,93 & $-0,41^{*}$ & $-0,09^{*}$ & $-0,08$ & $0,09^{*}$ & $0,16^{*}$ & $-0,32^{*}$ & $-0,28^{*}$ & $-0,28^{*}$ & $0,05^{*}$ \\
\hline Sociaal & 0,88 & $-0,24^{*}$ & $0,06^{*}$ & $0,10^{*}$ & $0,18^{*}$ & $0,24^{*}$ & $-0,19^{*}$ & $-0,09^{*}$ & $-0,17^{*}$ & $0,13^{*}$ \\
\hline Uiterlijk & 0,86 & $-0,23^{*}$ & $-0,02$ & $-0,07$ & 0,05 & $0,18^{*}$ & $-0,19^{*}$ & $-0,23^{*}$ & $-0,17^{*}$ & $0,11^{*}$ \\
\hline Prestatie & 0,87 & $-0,26^{*}$ & $-0,01$ & 0,02 & $0,19^{*}$ & $0,20^{*}$ & $-0,26^{*}$ & $-0,18^{*}$ & $-0,22^{*}$ & $0,06^{*}$ \\
\hline Instabiliteit & 0,96 & $0,28^{*}$ & $0,18^{*}$ & $0,17^{*}$ & $0,10^{*}$ & 0,04 & $0,21^{*}$ & $0,19^{*}$ & $0,20^{*}$ & 0,03 \\
\hline Narcisme & 0,86 & $-0,04$ & $0,07^{*}$ & $0,13^{*}$ & $0,15^{*}$ & $0,16^{*}$ & $-0,15^{*}$ & $-0,05^{*}$ & $-0,10^{*}$ & 0,02 \\
\hline Vijandigheid & & & & & & & & & & \\
\hline Globaal & 0,88 & $0,34^{*}$ & $0,24^{*}$ & $0,19^{*}$ & $0,13^{*}$ & 0,04 & $0,31^{*}$ & $0,26^{*}$ & $0,30^{*}$ & $0,07^{*}$ \\
\hline Sociaal & 0,87 & $0,35^{*}$ & $0,28^{*}$ & $0,15^{*}$ & 0,07 & $-0,04$ & $0,34^{*}$ & $0,23^{*}$ & $0,26^{*}$ & $-0,01$ \\
\hline Uiterlijk & 0,86 & $0,43^{*}$ & $0,30^{*}$ & $0,32^{*}$ & $0,15^{*}$ & 0,05 & $0,39^{*}$ & $0,33^{*}$ & $0,29^{*}$ & 0,00 \\
\hline Prestatie & 0,85 & $0,33^{*}$ & $0,30^{*}$ & $0,29^{*}$ & $0,19^{*}$ & 0,09 & $0,32^{*}$ & $0,26^{*}$ & $0,30^{*}$ & 0,04 \\
\hline
\end{tabular}

${ }^{*} p<0,01$. 
verklaard door de relatie tussen globale zelfwaardering en globale contingentie.

\section{Instabiliteit van zelfwaardering}

Rij vijf van tabel 7 vermeldt de correlaties van instabiliteit van zelfwaardering met de verschillende contingenties. Zoals verwacht (hypothese 2) is er een verband tussen globale contingentie en instabiliteit $(r=0,28)$. Dit verband wordt deels gemedieerd door globale zelfwaardering (partiële $r=0,18$ ). De correlaties van de domeinspecifieke contingenties met instabiliteit zijn zwakker en worden volledig verklaard door globale contingentie (partiële $r$ positief sociaal, uiterlijk, prestatie en intrinsiek resp. $0,06,0,08,0,02$ en 0,04 ; negatief sociaal, uiterlijk, prestatie en intrinsiek resp. 0,07, 0,07, 0,08 en 0,03 ).

\section{Narcisme}

In de zesde rij van de tabel staan de correlaties van narcisme met de verschillende contingenties weergegeven. Hypothese 3 wordt niet bevestigd, want er is geen verband tussen globale contingentie en narcisme. De positieve contingenties, met name prestatie en intrinsiek, vertonen wel significante positieve correlaties met narcisme, hetgeen hypothese $6 \mathrm{~b}$ bevestigt en hypothese $6 \mathrm{a}$ gedeeltelijk bevestigt (zie verder). De negatieve extrinsieke contingenties, met name sociaal, vertonen zwakke negatieve correlaties met narcisme.

\section{Vijandigheid}

In rij zeven van de tabel staan de correlaties van globale vijandigheid met de verschillende contingenties weergegeven. De correlatie van globale contingentie met globale vijandigheid bij egobedreiging is positief, zoals voorspeld in hypothese $4 \mathrm{a}(r=0,34)$. Ook hier is de evidentie voor de domeinspecifieke variant van de hypothese (hypothese 4b) zwakker. In de tabel zijn de correlaties van de domeinspecifieke contingenties met de specifieke vormen van vijandigheid onderstreept. De vet gedrukte correlaties zijn de correlaties tussen de corresponderende domeinen. De domeinspecifieke contingenties zijn positief gecorreleerd met domeinspecifieke vijandigheid, zoals voorspeld in hypothese $4 \mathrm{~b}$. Echter, deze correlaties worden lager wanneer er wordt uitgepartialiseerd voor globale contingentie. Ook hier zien we dus dat de meeste variantie wordt verklaard door de relatie tussen globale contingentie en vijandigheid bij egobedreiging in het algemeen.

De resultaten wijzen op een goede constructvaliditeit van de globale contingentieschaal, aangezien de schaal duidelijk correleert met de schalen van zelfwaardering, instabiliteit van zelfwaardering en vijandigheid. De schaal heeft ook een goede discriminante validiteit. De correlaties met globale zelfwaardering en instabiliteit van zelfwaardering zijn in de verwachte richting, maar zijn laag genoeg om te kunnen spreken van onderscheidbare constructen. De domeinspecifieke subschalen hebben een matige constructvaliditeit, aangezien de relaties van domeinspecifieke contingenties met andere variabelen grotendeels verklaard kunnen worden door globale contingentie.

Intrinsieke/extrinsieke en zelfwaardering verhogende/ verlagende contingenties

Onze verwachting was dat intrinsieke versus extrinsieke en zelfwaarderingverhogende versus -verlagende contingenties verschillend gerelateerd zouden zijn aan niveau van zelfwaardering, vijandigheid en narcisme.

\section{Zelfwaardering}

In de bovenste helft van tabel 7 is te zien dat, zoals verwacht, alle vormen van zelfwaardering (globaal, sociaal, uiterlijk en prestatie) positief gerelateerd zijn aan intrinsieke contingentie, hetgeen hypothese 5 a bevestigt. De correlaties met positieve intrinsieke contingentie blijken - zoals verwacht - sterker te zijn dan de correlaties met negatieve intrinsieke contingentie, maar de correlaties zijn over de hele linie zwak en de verschillen zijn klein. Van de extrinsieke contingenties die zelfwaardering verhogen, vertoont alleen prestatie een duidelijke positieve relatie met zelfwaardering (m.n. met sociale en prestatiezelfwaardering). Extrinsieke contingenties die zelfwaardering verlagen blijken inderdaad negatief gerelateerd te zijn aan zelfwaardering, zoals voorspeld in hypothese $5 \mathrm{~b}$, maar deze verbanden zijn zwak.

\section{Narcisme}

In tabel 7 is te zien dat, zoals verwacht (hypothese 6b), narcisme zwak maar significant positief gerelateerd is aan contingenties die zelfwaardering verhogen. Hypothese 6a wordt niet op consistente wijze bevestigd. Er is geen duidelijk onderscheid in het patroon van correlaties van intrinsieke en extrinsieke positieve contingenties met narcisme. Zowel uiterlijk, prestatie en intrinsiek vertonen soortgelijke relaties met narcisme. De correlaties van narcisme met extrinsieke contingenties die zelfwaardering verlagen zijn negatief. Dit geldt met name voor het sociale domein. De correlatie van narcisme met het negatieve intrinsieke domein is afwezig. 


\section{Vijandigheid}

De onderste helft van tabel 7 laat zien dat globale, sociale, uiterlijke en prestatievijandigheid, zoals verwacht (hypothese $7 \mathrm{a}$ ), positief gerelateerd zijn aan extrinsieke contingenties en nauwelijks gerelateerd aan intrinsieke contingenties. Extrinsieke contingenties die zelfwaardering verlagen, blijken iets sterker gerelateerd te zijn aan vijandigheid in vergelijking met extrinsieke contingenties die zelfwaardering verhogen, zoals voorspeld in hypothese $7 \mathrm{~b}$. Dit verschil is echter minimaal. De domeinspecifieke correlaties (domeinspecifieke vijandigheid/ domeinspecifieke contingentie) zijn vergelijkbaar met de globale correlaties (globale vijandigheid/globale contingentie), maar worden lager wanneer er wordt uitgepartialiseerd voor globale contingente zelfwaardering. Dit pleit niet voor een opsplitsing in acht factoren.

\section{Discussie}

Er werden twee Nederlandse vragenlijsten voor contingentie van zelfwaardering ontwikkeld: een vragenlijst die uitgaat van globale contingentie en een vragenlijst die uitgaat van domeinspecifieke contingentie. Een van onze doelen was na te gaan of contingentie een globaal (eendimensioneel) dan wel een domeinspecifiek (meerdimensioneel) kenmerk is. Aan de hand van de interne consistentie en factoriële, convergente, discriminante en constructvaliditeit van de schalen, werd de dimensionaliteit van contingentie onderzocht.

Voordat we op deze kwestie ingaan, is het van belang op te merken dat in ons onderzoek globale en specifieke contingentie heel verschillend zijn gemeten. Globale contingentie is gemeten met algemene stellingen, specifieke contingentie door een lijst van factoren waarop respondenten aangaven in hoeverre bepaalde factoren hun zelfwaardering verhoogden en verlaagden. Deze manier van meten moedigt deelnemers aan om zelf te differentiëren naar domeinen waarin ze meer en minder contingent zijn. Merk op dat we in beide metingen aannemen dat respondenten zelf inzicht hebben in de contingenties van hun zelfwaardering en bereid zijn hierover eerlijk te rapporteren. Gezien het feit dat de hypothesen grotendeels worden bevestigd, lijkt dit een redelijke aanname. Er zijn echter wel aanwijzingen dat inzicht in de eigen contingenties toeneemt wanneer de zelfwaardering wordt bedreigd (bijv. door sociale afkeuring of slechte prestaties) en dat dit inzicht zwakker is bij mensen die veel bevestiging krijgen en die geen ervaring hebben met een bedreiging van het zelfbeeld (Vonk, 2003; Vonk e.a., in voorbereiding). Dit kan gedeeltelijk de negatieve correlatie tussen zelfwaardering en contingentie verklaren.
Dat wil zeggen, mensen met een positief zelfbeeld kunnen deels minder contingent zijn, maar voor een ander deel is het ook zo dat ze zich minder bewust zijn van hun contingenties.

De resultaten van de factoranalyses lieten zien dat contingente zelfwaardering zowel globaal als domeinspecifiek te meten is. Beide schalen hebben goede interne consistenties.

Het verband tussen globale contingentie en instabiliteit was iets lager dan verwacht. Het is echter belangrijk te bedenken dat het om verschillende constructen gaat (Kernis, 2003). Contingente zelfwaardering hoeft niet te leiden tot instabiliteit, zolang de externe omstandigheden waar de zelfwaardering van afhangt niet veranderen (Deci \& Ryan, 1995; Crocker \& Wolfe, 2001).

Een andere factor die in ons onderzoek de resultaten heeft beïnvloed is dat de gegevens op verschillende tijdstippen zijn verzameld, doordat het ging om een langlopend onderzoek. De correlaties tussen alle variabelen zullen hierdoor enigszins zijn afgezwakt. Dit betekent dat onze toetsen enigszins conservatief zijn geweest. Bij meting binnen een en dezelfde vragenlijst zouden de correlaties hoger uitvallen.

Bij de domeinspecifieke meting bleek dat deelnemers die met name hoog scoorden op sociale factoren die de zelfwaardering verlagen (negatieve sociale contingentie, bijv. 'Genegeerd worden door anderen'), tevens hoger scoorden op globale contingentie. Ook scoorden zij hoger op zowel negatieve uiterlijke als negatieve prestatiecontingentie. Bovendien bleek negatieve sociale contingentie gepaard te gaan met een lage globale, sociale, uiterlijke en prestatiezelfwaardering en met een hoge globale, sociale, uiterlijke en prestatievijandigheid. Dit patroon van resultaten suggereert dat sociale negatieve contingentie in feite een zeer algemene contingentie weerspiegelt. Voor een deel is dit begrijpelijk, gezien het grote belang van sociale acceptatie en afwijzing (zie de sociometertheorie van Leary en Baumeister, 2000). Daarnaast vermoeden wij dat mensen met een hoge sociale negatieve contingentie geneigd zijn om veel situaties te interpreteren in termen van sociale afwijzing (vgl. een hoge afwijzingsgevoeligheid; Downey \& Feldman, 1996; Ayduk, May, Downey \& Higgins, 2003). Leveren deze mensen bijvoorbeeld een slechte prestatie of zien ze er slecht uit, dan zullen ze dit ook onmiddellijk koppelen aan mogelijke sociale afwijzing.

Door dit soort verbanden zal een onderscheid tussen verschillende specifieke vormen van contingentie in de praktijk niet altijd zinvol zijn. Dat bleek ook uit andere resultaten. De specifieke vormen van zelfwaardering correleerden zwak met specifieke contingenties, terwijl er wel een sterk verband was tussen globale contingentie en globale zelfwaardering. Dit patroon was ook te zien in 
de correlaties tussen contingentie en vijandigheid: de domeinspecifieke correlaties waren lager dan de globale correlaties. De resultaten zijn wat betreft vijandigheid in overeenstemming met studies van Olweus (1979) en Tangney e.a. (1996) waarin werd gevonden dat agressieve reacties over verschillende situaties heen consistent zijn. Iemand die dus bijvoorbeeld bij een sociale bedreiging van het ego agressief reageert, zal dit ook eerder doen in een prestatiegerelateerde situatie. Onze resultaten laten zien dat globale contingentie hierbij een belangrijke persoonlijkheidsvariabele is.

Wat betreft narcisme blijkt het onderscheid tussen verschillende specifieke contingenties juist weer zinvol te zijn. De resultaten lieten zien dat narcistische mensen gevoelig zijn voor positieve factoren, met name positieve prestatiefactoren (bijv. 'Goede prestaties leveren') en positieve intrinsieke factoren (bijv. 'Een nieuwe kant van mezelf ontdekken'), en dat ze ongevoelig zijn voor negatieve factoren, met name negatieve sociale factoren (bijv. 'Het gevoel hebben dat anderen me niet aardig vinden'). Deze combinatie van gevoeligheden en ongevoeligheden maakt dat de zelfwaardering van narcistische mensen in het algemeen niet snel aan het wankelen te brengen is. Narcistische mensen verlangen kennelijk naar erkenning van hun talenten en andere factoren waarover ze zelf controle lijken te hebben, en minder naar acceptatie door anderen. Deze conclusie komt overeen met de conclusie van Campbell, Rudich en Sedikides (2002), dat narcisten vinden dat ze bijzondere bekwaamheden hebben, en niet dat ze aardiger of moreler zijn dan anderen.

In onze studie werd ook exploratief gekeken naar de correlatie tussen narcisme enerzijds en globale en domeinspecifieke vijandigheid anderzijds. Deze correlaties bleken zwak te zijn $(r<0,10)$. Deze resultaten zijn in tegenspraak met de bevinding dat narcistische mensen geneigd zijn tot woede en agressie in reactie op negatieve feedback over hun prestaties (Rhodewalt \& Morf, 1998; Bushman \& Baumeister, 1998). In ons onderzoek is echter gebruik gemaakt van zelfrapportages. Doordat narcisme gekenmerkt wordt door een onrealistisch zelfbeeld kan het zijn dat narcistische mensen dénken dat negatieve factoren niet van invloed op hen zijn. Wanneer ze in de praktijk worden geconfronteerd met negatieve factoren, kan dit op gedragsniveau logischerwijs tot heel andere effecten leiden.

Het patroon van correlaties met de overige variabelen suggereert dat contingentie in de eerste plaats een algehele geneigdheid is (individuele verschilvariabele). De domeinspecifieke contingenties lijken in de meeste gevallen voornamelijk manifestaties te zijn van het onderliggende persoonskenmerk (globale contingente zelfwaardering). De relaties van de domeinspecifieke contingenties met andere variabelen kunnen grotendeels worden verklaard door globale contingentie.

Voor de meeste doeleinden zal een globale meting van contingente zelfwaardering voldoende zijn. Zowel in wetenschappelijk onderzoek als in de praktijk is globale contingente zelfwaardering een belangrijke variabele. Onze resultaten laten zien dat hoge globale contingentie gepaard gaat met lage zelfwaardering, instabiele zelfwaardering en hoge vijandigheid bij bedreiging. Eerder onderzoek liet tevens zien dat een hoge globale contingentie gerelateerd is aan een hogere alcoholconsumptie en aan alcoholgerelateerde problemen (Neighbors, Larimer, Geisner \& Knee, 2001, in Kernis, 2003). Het is dus raadzaam om contingentie van zelfwaardering in beschouwing te nemen in onderzoek naar het zelfbeeld, aangezien een hoge mate van contingentie nogal wat nadelige gevolgen kan hebben.

Als het inderdaad zo is, zoals onze resultaten suggereren, dat er stabiele individuele verschillen zijn tussen mensen in de mate van globale contingentie, dan zal het moeilijk zijn iemands contingentie te verminderen. Het is echter misschien wel mogelijk om kwetsbare contingentiegebieden (bijv. sociale acceptatie en uiterlijk) te verschuiven naar gebieden die men meer zelf in de hand heeft (bijv. intrinsieke en prestatiefactoren). Onze resultaten lieten bijvoorbeeld zien dat hoge uiterlijke contingentie samengaat met lage zelfwaardering en hoge vijandigheid, en dat hoge intrinsieke contingentie samengaat met hoge zelfwaardering en lage vijandigheid. Wanneer men het belang dat een individu toedicht aan bepaalde contingenties zou kunnen verschuiven, zou dit kunnen bijdragen aan een beter psychologisch functioneren. In die zin kan onderzoek naar contingentie ook een bijdrage leveren aan hulpverlening voor mensen die worstelen met contingente zelfwaardering.

Samenvattend levert ons onderzoek $a$ een betrouwbare Nederlandse vragenlijst voor zowel globale als domeinspecifieke contingente zelfwaardering, en $b$ aanwijzingen dat contingente zelfwaardering in de eerste plaats een globale individuele verschilvariabele is, die systematisch gerelateerd is aan andere variabelen. Meer inzicht in de belangrijke rol van contingente zelfwaardering kan niet alleen bijdragen aan verdere theorievorming over het zelfbeeld, maar ook aan een betere hulpverlening voor mensen met een kwetsbaar zelfbeeld.

Ontvangen: 28 mei 2004; geaccepteerd: 12 december 2004. Jansen, D.L., \& Vonk, R. (2005). Contingent self-esteem: Reliability and validity of the Dutch global and domain-specific contingency scales. Nederlands Tijdschrift voor de Psychologie, 60, 1-14.

Contingent self-esteem is dependent on certain factors, such as one's physical appearance, achievements or approval from others. 
Two Dutch scales were developed: one based on global contingency (contingency of self-esteem as a global individual differences variable) and one based on domain-specific contingency (in which people differ merely in the domains on which they are contingent, for example achievements vs. acceptance). Both scales were examined for internal consistency and factorial, convergent, discriminate and construct validity. The results suggest that, for most purposes, a global approach to contingency will suffice; in general, domainspecific contingencies are mainly manifestations of the overall tendency to derive self-esteem from certain factors. Contingency is positively related to hostility and instability of self-esteem and negatively to level of self-esteem.

\section{Literatuur}

Arbuckle, J.L., \& Wothke, W. (1999). Amos 4.0 users's guide. Chicago, IL: SmallWaters.

Ayduk, O., May, D., Downey, G., \& Higgins, E.T. (2003). Tactical differences in coping with rejection sensitivity: The role of prevention pride. Personality and Social Psychology Bulletin, 29, 435-448

Baumeister, R.F., Campbell, J.D., Krueger, J.I., \& Vohs, K.D. (2003). Does high self-esteem cause better performance, interpersonal success, happiness, or healthier lifestyles? Psychological Science in the Public Interest, 4, 1-44.

Baumeister, R.F., \& Leary, M.R. (1995). The need to belong: Desire for interpersonal attachments as a fundamental human motivation. Psychological Bulletin, 117, 497-529.

Baumeister, R.F., Smart, L., \& Boden, J.M. (1996). Relation of threatened egotism to violence and aggression: The dark side of high self-esteem. Psychological Review, 103, 5-33.

Bentler, P.M. (1983). Some contributions to efficient statistics for structural models: Specification and estimation of moment structures. Psychometrika, 48, 493-571.

Bentler, P.M., \& Bonett, D.G. (1980). Significance tests and goodness of fit in the analysis of covariance structures. Psychological Bulletin, 88, 588-606.

Browne, M.W., \& Cudeck, R. (1993). Alternative ways of assessing model fit. In K.A. Bollen \& J.S. Long (Eds.), Testing structural equation models (pp. 136-162). Newbury Park, ca: Sage.

Bushman, B.J., \& Baumeister, R.F. (1998). Threatened egotism, narcissism, self-esteem, and direct and displaced aggression: Does self-love or self-hate lead to violence? Journal of Personality and Social Psychology, 75, 219-229.

Campbell, W.K., Rudich, E.A., \& Sedikides, C. (2002). Narcissism, self-esteem, and positivity of self-views: Two portraits of selflove. Personality and Social Psychology Bulletin, 28, 358-368.

Crocker, J., Karpinski, A., Quinn, D.M., \& Chase, S.K. (2003). When grades determine self-worth: Consequences of contingent self-worth for male and female engineering and psychology majors. Journal of Personality and Social Psychology, 85, 507-516.

Crocker, J., \& Luhtanen, R.K. (2003). Level of self-esteem and contingencies of self-worth: Unique effects on academic, social and financial problems in college students. Personality and Social Psychology Bulletin, 29, 701-712.

Crocker, J., Luhtanen, R.K., Cooper, M.L., \& Bouvrette, A. (2003). Contingencies of self-worth in college students: Theory and measurement. Journal of Personality and Social Psycho$\log y, 85,894-908$.

Crocker, J., Sommers, S.R., \& Luhtanen, R.K. (2002). Hopes dashed and dreams fulfilled: Contingencies of self-worth and graduate school admissions. Personality and Social Psychology Bulletin, 28, 1275-1286.
Crocker, J., \& Wolfe, C.T. (2001). Contingencies of self-worth. Psychological Review, 108, 593-623.

Deci, E.L., \& Ryan, R.M. (1985). Intrinsic motivation and selfdetermination in human behavior. New York: Plenum.

Deci, E.L., \& Ryan, R.M. (1995). Human autonomy: The basis for true self-esteem. In M.H. Kernis (Ed.), Efficacy, agency, and self-esteem (pp. 31-49). New York: Plenum.

Downey, G., \& Feldman, S.I. (1996). Implications of rejection sensitivity for intimate relationships. Journal of Personality and Social Psychology, 70, 1327-1343.

Emmons, R.A. (1987). Narcissism: Theory and measurement. Journal of Personality and Social Psychology, 52, 11-17.

Greenier, K.D., Kernis, M.H., \& Waschull, S.B. (1995). Not all high (or low) self-esteem people are the same: Theory and research on stability of self-esteem. In M.H. Kernis (Ed.), Efficacy, agency, and self-esteem (pp. 51-71). New York: Plenum.

Heatherton, T.F., \& Polivy, J. (1991). Development and validation of a scale for measuring state self-esteem. Journal of Personality and Social Psychology, 60, 895-910.

Hu, L., \& Bentler, P.M. (1998). Fit indices in covariance structure modeling: Sensitivity to underparameterized model misspecification. Psychological Methods, 3, 424-453.

Kernis, M.H. (2003). Toward a conceptualization of optimal selfesteem. Psychological Inquiry, 14, 1-26.

Kernis, M.H., Grannemann, B.D., \& Barclay, L.C. (1989). Stability and level of self-esteem as predictors of anger arousal and hostility. Journal of Personality and Social Psychology, 56, 1013-1023.

Kirkpatrick, L.A., Waugh, C.E., Valencia, A., \& Webster, G.D. (2002). The functional domain specificity of self-esteem and the differential prediction of aggression. Journal of Personality and Social Psychology, 82, 756-767.

Leary, M.R., \& Baumeister, R.F. (2000). The nature and function of self-esteem: Sociometer theory. In M. Zanna (Ed.), Advances in experimental social psychology (pp. 1-62). San Diego, CA: Academic Press.

Leary, M.R., \& Downs, D.L. (1995). Interpersonal functions of the self-esteem motive: The self-esteem system as a sociometer. In M.H. Kernis (Ed.), Efficacy, agency, and self-esteem (pp. 123144). New York: Plenum.

Morf, C.C., \& Rhodewalt, F. (2001). Unraveling the paradoxes of narcissism: A dynamic self-regulatory processing model. Psychological Inquiry, 12, 177-196.

Olweus, D. (1979). Stability of aggressive reaction patterns in males: A review. Psychological Bulletin, 86, 852-875.

Paradise, A.W., \& Kernis, M.H. (1999). Contingent Self-Esteem Scale. (Ongepubliceerd.)

Rhodewalt, F., Madrian, J.C., \& Cheney, S. (1998). Narcissism, self-knowledge organization, and emotional reactivity: The effect of daily experiences on self-esteem and affect. Personality and Social Psychology Bulletin, 24, 75-87.

Rhodewalt, F., \& Morf, C.C. (1998). Self-aggrandizement and anger: A temporal analysis of narcissism and affective reactions to success and failure. Journal of Personality and Social Psychology, 74, 672-685.

Rosenberg, M. (1965). Society and the adolescent self-image. Princeton, NJ: Princeton University Press.

Ryan, R.M., \& Deci, E.L. (2000). Self-determination theory and the facilitation of intrinsic motivation, social development, and well-being. American Psychologist, 55, 68-78.

Tafarodi, R.W., \& Swann, W.B., Jr. (1995). Self-liking and selfcompetence as dimensions of global self-esteem: Initial validation of a measure. Journal of Personality Assessment, 65, 322-342.

Tangney, J.P., Hill-Barlow, D., Wagner, P.E., Marschall, D.E., Borenstein, J.K., Sanftner, J., Mohr, T., \& Gramzow, R. 
(1996). Assessing individual differences in constructive versus destructive responses to anger across the lifespan. Journal of Personality and Social Psychology, 70, 780-796.

Tangney, J.P., Hill-Barlow, D., Wagner, P.E., Marschall, D.E., Borenstein, J.K., Sanftner, J., Mohr, T., \& Gramzow, R. (1996). Anger response inventories. (Ongepubliceerd.)
Vonk, R. (2003). Zelfwaardering bestaat niet. (Presentatie jaarlijks congres van de Associatie voor Sociaal Psychologisch Onderzoek. Maastricht, december 2003.)

Vonk, R., Jolij, J., Stoeller, T., \& Boog, I. (2004). Effects of unconditional positive regard and self-reflection on self-esteem. (In voorbereiding.) 